\title{
STRENGTH OF MIG WELDED CONNECTIONS IN FIRE EXPOSED ALUMINIUM STRUCTURES
}

\author{
J. Maljaars ${ }^{1, *}$ and F. Soetens ${ }^{2}$ \\ ${ }^{1}$ TNO Built Environment \\ and Geosciences. Address: TNO; P.O. Box 49; 2600 AA Delft; The Netherlands \\ Tel +31152763464 . Fax. +31152763018 \\ ${ }^{2}$ Eindhoven University of Technology / TNO Built Environment and Geosciences. Address: TNO; \\ P.O. Box 49; 2600 AA Delft; The Netherlands \\ Tel +31 152763468 . Fax. +31 152763018 \\ *(Corresponding author: E-mail: johan.maljaars@tno.nl)
}

\begin{abstract}
Aluminium alloy structures are sensitive to fire exposure, which is mainly due to the low melting temperature. Yet a complete knowledge of the structural behaviour of aluminium alloys when exposed to fire is not available. This paper focuses on one of the main knowledge gaps, being the strength of aluminium welded connections in fire. Uniaxial tensile tests were carried out at elevated temperatures on welded and unwelded aluminium samples of alloys 5083-H111, 6060-T66 and 6082-T6. All welded samples failed outside the weld itself. It is concluded that the difference in strength between the heat affected zone and the parent metal decreases with increasing temperature.
\end{abstract}

Keywords: Fire design, heat affected zone, treatment, precipitation hardening

\section{INTRODUCTION}

Aluminium alloys are widely used in structures such as boats, trains, parts of drill platforms (mainly the helicopter deck and the living quarters) and roofs with large spans. The main reason for applying aluminium alloys in these structures is often the high ratio between strength and density. One of the aspects that should be checked in the design of these structures is fire resistance.

The strength of most commercially applied aluminium alloys reduces from $90 \%$ to $20 \%$ of the strength at room temperature at temperatures between $150{ }^{\circ} \mathrm{C}$ and $350{ }^{\circ} \mathrm{C}$ (Lundberg [1]). These temperatures are low for fire exposure: the standard temperature-time curve (ISO 834) gives a gas temperature after 30 minutes of $840{ }^{\circ} \mathrm{C}$. Besides, aluminium alloy members heat up relatively fast, mainly because of the high thermal conductivity $(110-250 \mathrm{~W} / \mathrm{mK}$ for most alloys, Kammer [2]). This makes aluminium alloy structures sensitive to fire exposure. Many aluminium structures have to be insulated in order to meet fire resistance requirements (Maljaars et al. [3]).

Because of the sensitivity to fire of aluminium alloys, fire design is a major aspect in the total design of aluminium structures for which requirements are set on the fire resistance (such as the structures mentioned above). The most up-to-date standard for structural fire design of aluminium structures is Eurocode 9, Part 1-2 (EN 1999-1-2 [4]). However, the standard does not give a complete set of verification rules for all possible failure mechanisms of structures and structural components. This is due to a lack of fundamental research concerning these failure mechanisms.

This paper focuses on one of the knowledge gaps, being the strength of welds when exposed to fire. If the design is performed applying simple calculation models, EN 1999-1-2 [4] states that the connection need not be checked, provided that the thermal resistance of the fire protection at the connection is equal to or larger than the thermal resistanceof the fire protection of the adjacent member (It is implicitly assumed that the design of the members and connections at ambient temperature is correct, e.g. based on EN 1999-1-1 [5], and that the utilisation of the connection is not higher than the utilisation of the connected members). Research has been carried out to verify 
this statement for welded aluminium structures.

The paper starts with the state-of-the-art design of welded connections. Subsequently, results of a literature survey into the strength of alloys at elevated temperature are discussed. Finally, results of tests carried out on the strength of welded aluminium alloy specimens at elevated temperature are given and discussed.

In order to comprehend the data and discussions in this paper, background information on the treatment options and strength enhancement of aluminium alloys is a prerequisite. This information is provided in text books such as Altenpohl [6], or articles such as Gitter [7].

\section{STATE OF THE ART: STRENGTH OF ALUMINIUM MIG WELDED CONNECTIONS AT ROOM TEMPERATURE}

\subsection{Qualitative Explanation of the Relative Strength of the Heat Affected Zone and the Weld Metal}

MIG welding is currently the most commonly used welding process for the structures mentioned in the introduction. In this welding process, two members are joined by melting the parent metal, while adding a suitable filler metal. The MIG welding process results in two potentially weak parts of the connection, being:

1. The weld metal itself, which is a mixture of parent metal and filler metal. This weld metal may have a lower strength than the parent metal.

2. The zone that is affected by the heat input of the welding process (the heat affected zone, HAZ). Due to the heat input of the welding process, recovery and overageing or annealing reduce the strength compared to treated (hardened) parent metal (see the Annex).

Figure 1 gives an overview of the hardness of the HAZ.
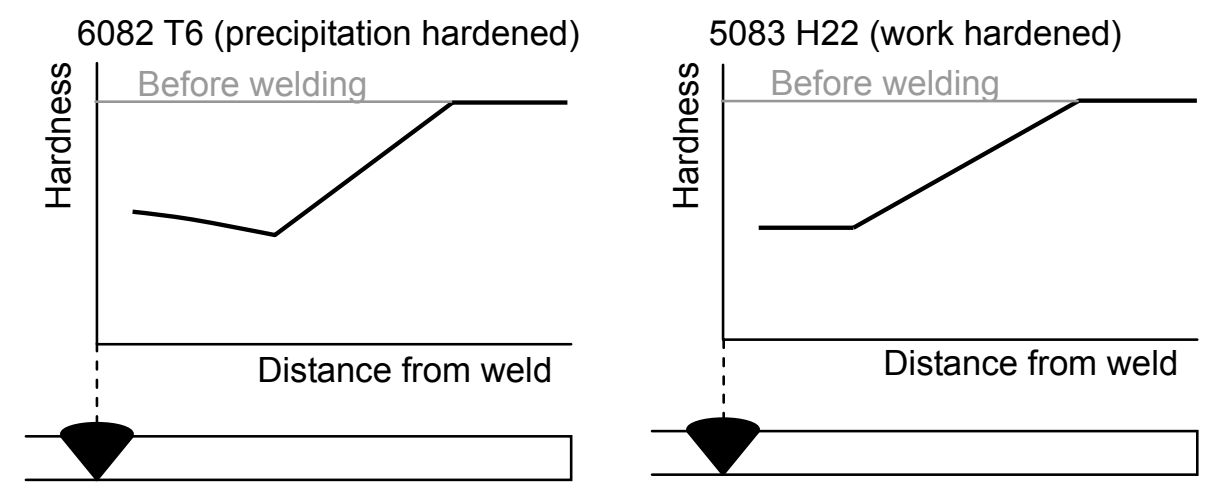

Figure 1. Hardness of the HAZ of Alloys 6082-T6 and 5083 H22 (After Dwight [8])

\subsection{Strength Design Values in Eurocode 9, Part 1-1}

Aluminium alloys have a curved stress-strain $(\sigma-\varepsilon)$ relationship. In most standards, the value of the $0.2 \%$ proof stress $f_{0.2}$ (i.e. the stress at a plastic strain of $0.2 \%$ ) is applied in the verification rules for the structural design of aluminium structures at room temperature. Among these standards is Eurocode 9, Part 1-1 (EN 1999-1-1 [5]). 
For the weld metal and the HAZ at connections, however, the ultimate tensile strength $f_{u}$ may be applied in the verification rules in EN 1999-1-1. Thus, plastic deformation is allowed over the small length of the weld zone and the HAZ. As an example, Figure 2 gives the stress-strain curves resulting from tests for the parent metal, the HAZ and the weld metal of alloy 6082-T6. Especially for precipitation hardened alloys, $f_{u}$ of the HAZ (or weld metal) is in many cases lower than $f_{0.2}$ of the parent metal.

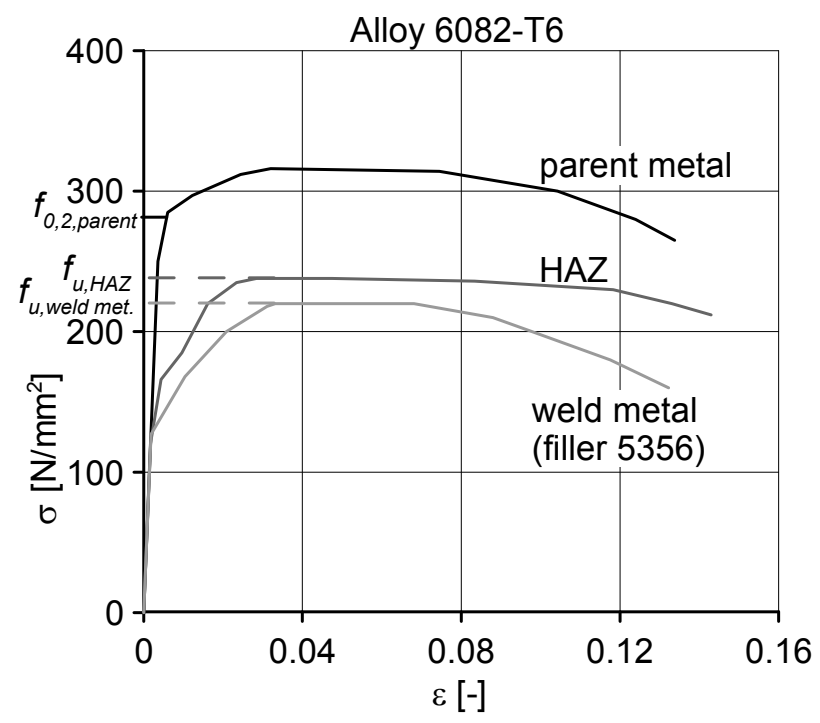

Figure 2. $\sigma-\varepsilon$ Relationship of Parent Metal, Heat Affected Zone and Weld Metal According to Tests on Alloy 6082-T6 (Thickness 4 mm, Filler Metal 5356. Source: Soetens [9])

\section{LITERATURE SURVEY: STRENGTH OF PARENT METAL AT ELEVATED TEMPERATURE}

\subsection{Data Sources}

In order to determine the constitutive properties at elevated temperature, two types of (uniaxial tensile) tests can be carried out:

1. Steady state tests. The specimen is subjected to a constant, elevated temperature in time, while a certain strain rate is applied (i.e. a displacement-controlled test). The actual test is preceded by a period with a constant temperature equal to the test temperature (the thermal exposure period).

2. Transient state tests. The test is carried out at a certain stress level and an increasing temperature in time. The deformation (strain) is monitored. Usually, a constant heating rate and a constant stress level in time are applied.

Although transient state tests are widely considered as being more appropriate for fire design, only the results of steady state tensile tests are found in literature for aluminium alloys. The strength data in EN 1999-1-2 are also based on steady state tests (Lundberg [1]). Steady state tensile tests on various alloys with various exposure periods are reported in Voorhees and Freeman [10] and Kaufman [11]. The alloys incorporated in these reports are limited to those frequently applied in the USA. Tensile tests on alloy 6082, frequently applied in Europe, are reported in Hepples and Wale [12] and Langhelle [13]. These test results are discussed in this section, separately for precipitation hardened (6xxx series) and for work hardened (5xxx series) alloys. 
It has been shown in many tests, e.g. Kumar and Swaminathan [14] and Van den Boogaard [15], that the stress-strain relation depends on the strain rate applied in a steady state tensile test, especially at elevated temperatures. At elevated temperatures, a higher strain rate results in a higher strength. The strain rate applied in the tests mentioned above is in most cases approximately $0.005 /$ min up to yielding and 0.05 to 0.10 / min up to rupture.

Maljaars et al (Heron [16]) showed that the strength degradation is approximately equal for alloys in the same series and temper.

\subsection{Precipitation Hardened Alloys}

As an example, the reduction of $f_{0.2}$ as a function of the temperature $\theta$ of the precipitation hardened alloy 6063 is given in Figure 3a. The strength of artificially aged tempers (T5-T9, see the Annex) reduces fast with temperature. Contrarily, the strength of naturally aged tempers (T1-T4) increases at moderately elevated temperatures, which is attributed to artificial ageing. At higher temperatures, the strength of artificially and of naturally aged tempers are (almost) equal to one another. At even higher temperatures, the strength of precipitation hardened tempers approaches that of the alloy in annealed temper.

The data in the literature show that the strength depends on the thermal exposure period in case of precipitation hardened alloys. This is due to the fact that the influence of overageing is a function of the time at elevated temperature.

\subsection{Work Hardened Alloys}

An example of the reduction of $f_{0.2}$ as a function of $\theta$ of the work hardened alloy 5052 is given in Figure $3 \mathrm{~b}$. The strength of the work hardened temper reduces faster than the strength of the annealed temper. The difference in strength for different tempers reduces as the temperature increases. This is attributed to recovery and annealing. The data in literature show that the strength of most work hardened alloys is independent of the thermal exposure period, for the tests carried out with a thermal exposure period of 30 up to 600 minutes.
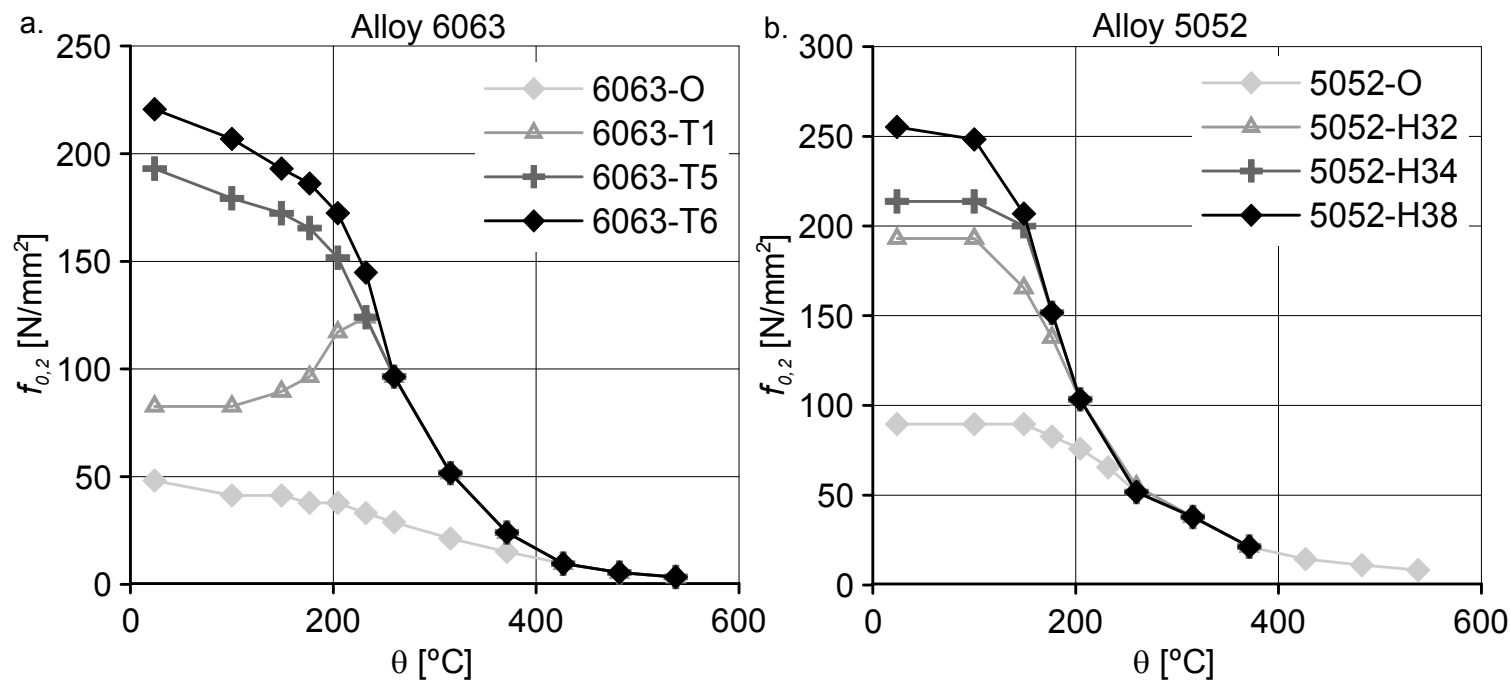

Figure 3. $f_{0.2}$ as Function of $\theta$ for a. Alloy 6063-T6 and b. Alloy 5052 (Data source: Kaufman [11]. The Data Shown are Average Values Resulting from a Large Number of Tests. The Design Values for $f_{0.2}$ are Lower. The Results for Temper T1 are also Representative for T4.) 
Considering all the data found in literature, it is concluded that work hardening and/or precipitation hardening may increase the strength in a substantial way at room temperature, but it has almost no effect at temperatures above $150-200{ }^{\circ} \mathrm{C}$ (i.e. the relevant temperatures for fire design). The favourable metal structure obtained by the treatment is (partially) destroyed when exposed to an elevated temperature either during a minimum period of time or at a sufficiently high temperature. This is similar to the influence of welding.

\section{TESTS: STRENGTH OF WELDS AT ELEVATED TEMPERATURE}

\subsection{Fire Resistance of Connections According to Standards}

A simple calculation model in EN 1999-1-2 [4] states that the fire resistance of the connections need not be checked, provided that the thermal resistance of the fire protection at the connection is equal to or larger than the thermal resistance of the fire protection of the adjacent member, as mentioned before in the introduction. A similar statement is made in Eurocode 3, Part 1-2 (EN 1993-1-2 [17]) for the fire design of steel structures. The statement is based on the fact that, if the above condition of the fire protection is fulfilled, the temperature development of, for example, beam to column connections is usually behind the temperature development of the adjacent members (Franssen and Zacharia [18]).

This statement may be justified for simple calculation models of steel members. The specific strength characteristics of aluminium welds, with its filler metal and heat affected zones, however, may require a different approach. Besides, in the case of advanced calculation models, restrained thermal expansion and changing stiffness ratios of the adjacent members have to be taken into account. In such cases it is necessary to know the strength of the connection in more detail.

In order to determine the strength of the HAZ and the weld metal in relation to the parent metal, uniaxial tensile tests need to be carried out on specimens with and without welds.

\subsection{Test Programme}

Three types of specimens were used in the test programme:

a) Specimens without welds. The specimens are flat, so-called disproportional specimens, with dimensions according to Figure 5a. The tests on these specimens are referred to as "reference tests".

b) Specimens with fillet welds. The specimens consist of two parts, with a horizontal plate welded in between (Figure 5b). The fillet welds are overmatched, so that rupture does not take place at the weld itself. These specimens are indicated with "fillet weld specimens".

c) Specimens with butt welds. The specimens consist of two parts, welded together with an $\mathrm{X}$-shaped weld (Figure 5c). Due to the MIG welding process, the weld throat is slightly larger than the specimen thickness. In conformity with custom practice for the structures mentioned in the introduction, the welds are as fabricated. The indication is "butt weld specimens".

All welded specimens were cut from a larger, welded plate (Figure 6), so that start-stop positions are not present in the specimens. 
a)

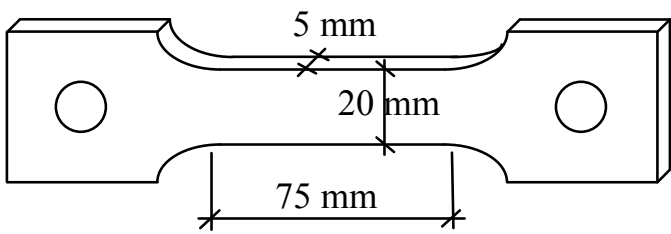

b)

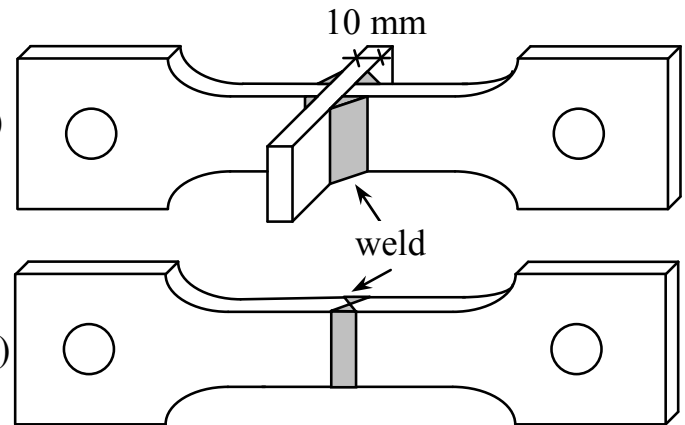

Figure 5. Overview of Tested Specimens for the Strength Measurements

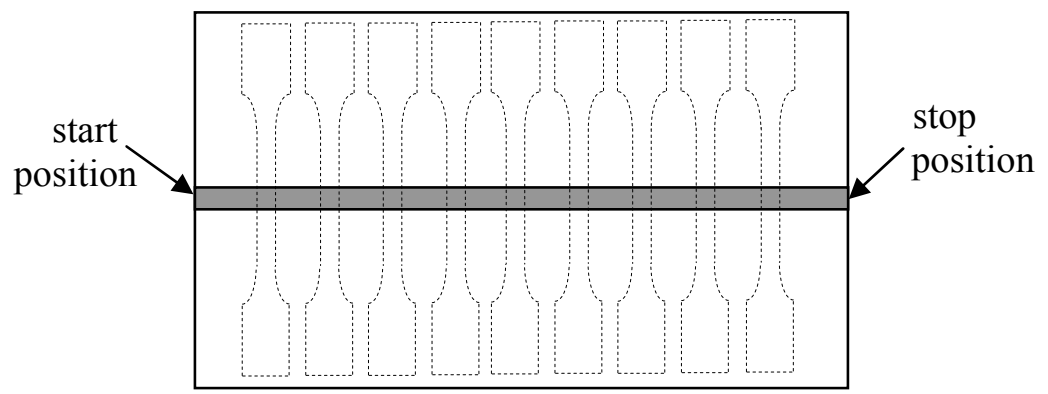

Figure 6. Production of the Specimens from a Larger, Welded Plate

Two types of tests were applied:

- Steady state tests carried out at $20{ }^{\circ} \mathrm{C}, 200{ }^{\circ} \mathrm{C}$ and $300{ }^{\circ} \mathrm{C}$. The elevated temperatures were selected such that the temperature range relevant for fire design was covered. The test procedure applied in the tests was as follows:

1. Heating the specimen from room to test temperature in approximately 25 minutes.

2. Maintaining the test temperature constant for approximately 15 minutes.

3. Applying a certain strain rate (cross-head motion) until rupture occurred. In agreement with EN 10002-5 [19], the strain rate measured over the parallel length was $0.006 / \mathrm{min}$ in the elastic range and then gradually increased to $0.03 / \mathrm{min}$ at the ultimate resistance.

- Transient state tests, carried out with constant heating rates of 6 and $12{ }^{\circ} \mathrm{C} / \mathrm{min}$. These heating rates are representative for heating of fire exposed insulated aluminium members. The stress applied in the transient state test was equal to the ultimate tensile strength determined in the steady state tests on the reference specimens at $300{ }^{\circ} \mathrm{C}$. Only a limited number of transient state tests were carried out. The purpose of these tests was to check whether the conclusions of the steady state tests also apply to transient state conditions.

Three alloys were used in the test programme:

- Alloy 5083-H111. Temper H111 indicates that this alloy is almost in annealed temper (O). The filler weld metal is alloy 5356;

- Alloy 6060-T66. This is a fully heat treated (precipitation hardened, artificially aged) alloy, with higher strength values than the alloy in temper T6. The filler metal is alloy 4043;

- Alloy 6082-T6. The filler metal is alloy 4043. Only steady state tests on reference specimens and butt weld specimens were carried out on this alloy. 
The test program is summarised in tables 1 and 2. The number of tests is indicated between brackets

Table 1. Overview of Steady-state Test Program

\begin{tabular}{|c|c|c|c|}
\hline Test temp. & a) reference spec. & b) fillet weld spec. & c) butt weld spec. \\
\hline $20{ }^{\circ} \mathrm{C}$ & $\begin{array}{l}5083(3) \\
6082(2)\end{array}$ & $5083(3) \quad 6060(3)$ & $\begin{array}{l}5083(2) \quad 6060(2) \\
6082(2)\end{array}$ \\
\hline $200^{\circ} \mathrm{C}$ & $\begin{array}{l}5083(4) \\
6060(3) \\
6082(2)\end{array}$ & $5083(3) \quad 6060(2)$ & $\begin{array}{l}5083(2) \\
6060(2) \\
6082(2)\end{array}$ \\
\hline $300^{\circ} \mathrm{C}$ & $\begin{array}{l}5083(3) \quad 6060(3) \\
6082(2)\end{array}$ & $5083(2) \quad 6060(2)$ & $\begin{array}{l}5083(2) \quad 6060(2) \\
6082(2)\end{array}$ \\
\hline
\end{tabular}

Table 2 Overview of transient state test program

\begin{tabular}{|c|c|c|c|}
\hline Heating rate & a) reference spec. & b) fillet weld spec. & c) butt weld spec. \\
\hline $6^{\circ} \mathrm{C} / \mathrm{min}$ & $5083(1) 6060(1)$ & $6060(1)$ & $5083(1)$ \\
\hline $12^{\circ} \mathrm{C} / \mathrm{min}$ & $6060(1)$ & $5083(1) \quad 6060(1)$ & \\
\hline
\end{tabular}

\subsection{Test Set-up}

The tests were carried out in a conventional electrical furnace, with an actuator supplied with a 100 $\mathrm{kN}$ load cell outside the furnace. The force was transmitted by means of a bar that penetrates the furnace wall. Figure 7 gives an overview of the test set-up.

Thermocouples were used for measuring the temperature at the upper part, the centre and the lower part of the parallel length of the specimens. The furnace temperature was controlled in such a way, that the measured temperature of the specimen was in accordance with the specifications in tables 1 and 2. The temperature of the upper part of the parallel length was approximately $2{ }^{\circ} \mathrm{C}$ warmer than the lower part in all tests at elevated temperature.

4 linear variable differential transformers (LVDTs) outside the furnace were used for determining the axial deformation. The measured length was equal to $50 \mathrm{~mm}$, applied at the upper part of the parallel length of $75 \mathrm{~mm}$ (Figure 8). The measured length was outside the centre of the specimen, because rupture was expected in the upper part of the specimen due to the slightly higher temperature in the upper part. A clamp was applied around the specimen, in such a way that the displacements of the lower and the upper side of the measured length were measured at both sides of the specimen (i.e. 4 displacement measurements per specimen). Invarsteel pins were applied between the clamp inside the furnace and the 4 LVDTs outside the furnace (Figure 8). 

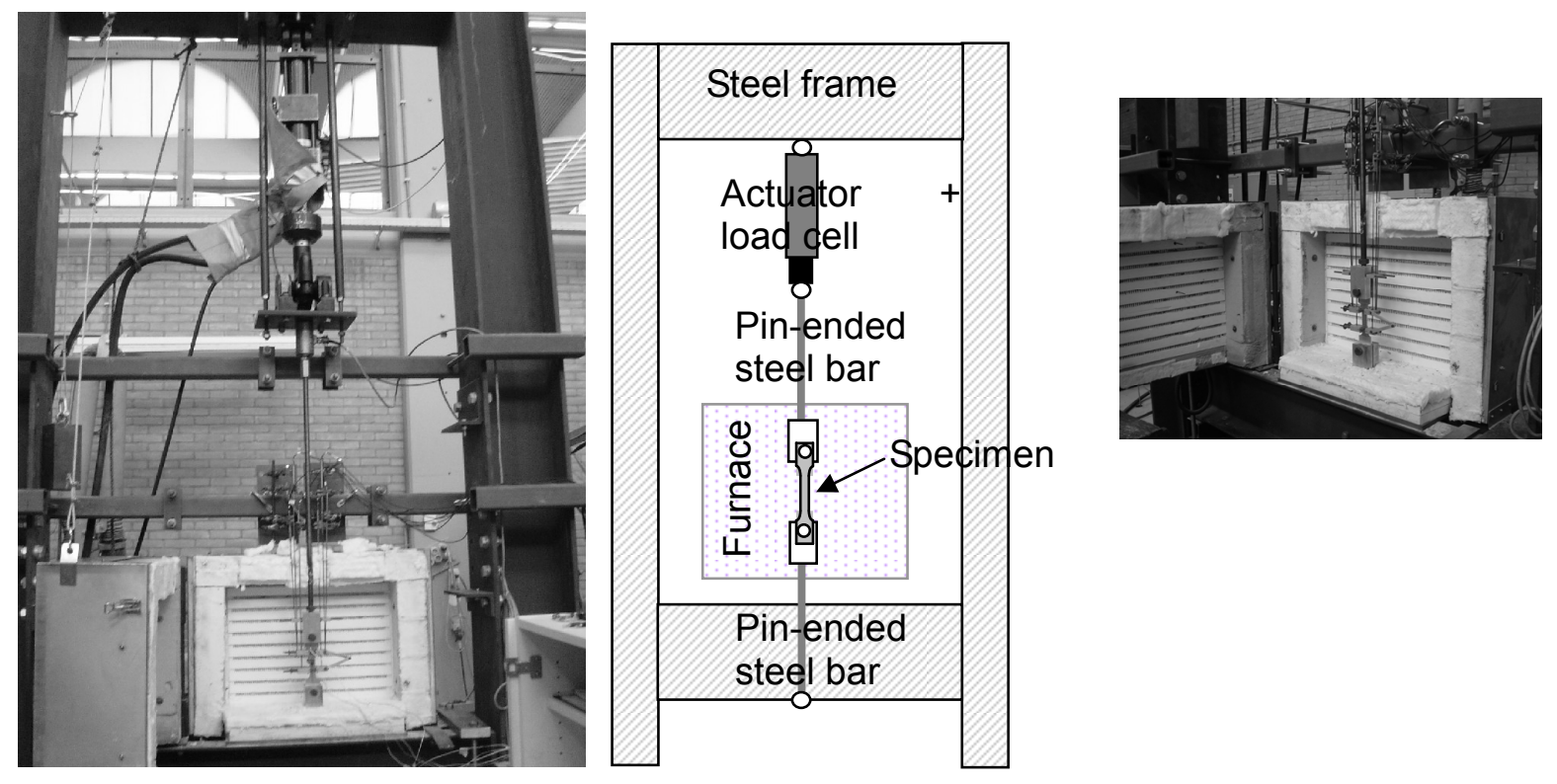

Figure 7. Overview of the Test Set-up
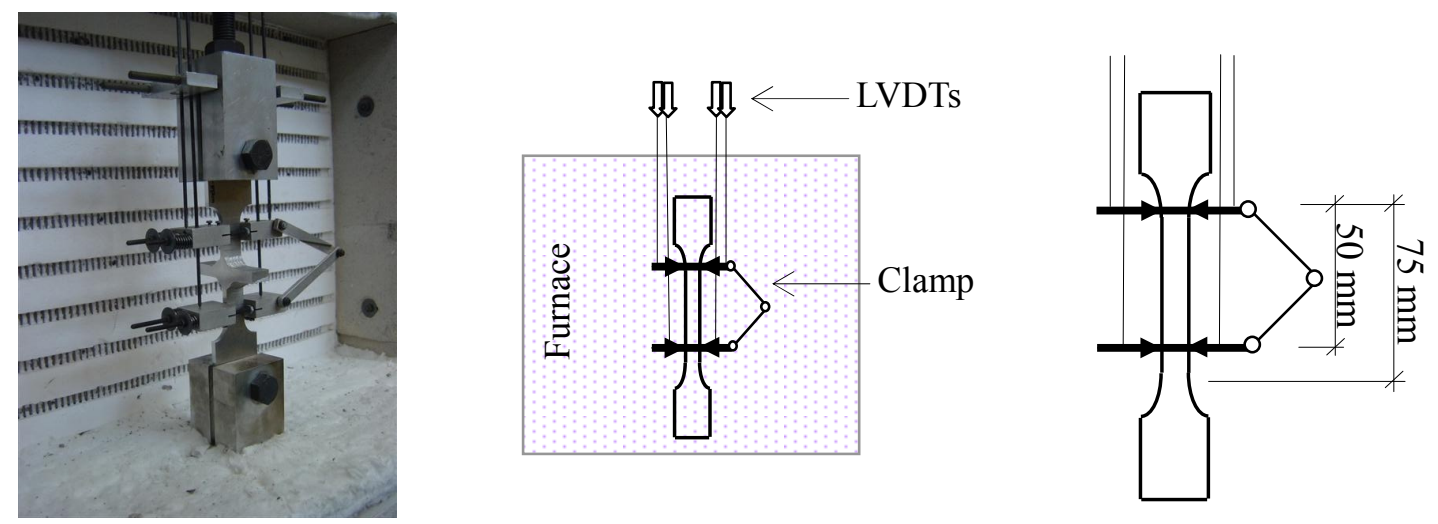

Figure 8. Specimen with the Clamp for the LVDTs

With this measurement system, the displacements of the steady state tests could be determined with sufficient accuracy, as the temperature was constant during these tests. For transient state tests, however, the measurements on the mechanical displacements of the specimens was less accurate, due to the thermal expansion of the measurement devices and specimens during these tests.

The strain at rupture could not be determined accurately, as the clamp lost contact with the specimens due to thermal expansion of the clamp and lateral contraction of the specimen. However, this research focused on the ultimate tensile strength.

\subsection{Test Results}

\section{Steady State Tests}

The tests carried out at the same temperature resulted in equal $\sigma-\varepsilon$ relationships. The difference in ultimate tensile strength between the steady state tests carried out was on average $4 \mathrm{~N} / \mathrm{mm}^{2}(2.5 \%)$ and maximum $11 \mathrm{~N} / \mathrm{mm}^{2}$. Thus the tests are well reproducible. 
Figure 9 gives the $\sigma-\varepsilon$ relationships of a selection of the steady-state tests on alloy 5083-H111. As the temperature increased, the amount of strain hardening and the homogeneous strain decreased. This was found for all specimens and all alloys of the test program.

Figure 10a. gives the ultimate tensile strength $f_{u}$ as a function of the temperature $\theta$ for the reference and the welded specimens of alloy 5083-H111. For reasons of comparison, the Figure also gives the strength data of the parent metal of alloy 5083-O according to Kaufman [11].

Note that alloy 5083-H111 is (almost) not treated. Both at room and at elevated temperature, the strength of the welded specimens was approximately equal to that of the reference specimens.

At room temperature, rupture took place in the centre of the specimens, both for the reference and the welded specimens. At elevated temperatures $\left(200\right.$ and $\left.300{ }^{\circ} \mathrm{C}\right)$, rupture occurred in the upper part of the specimens, where the temperature was slightly higher (Figure 10b.). This means that the welded specimens failed outside the HAZ at elevated temperature.

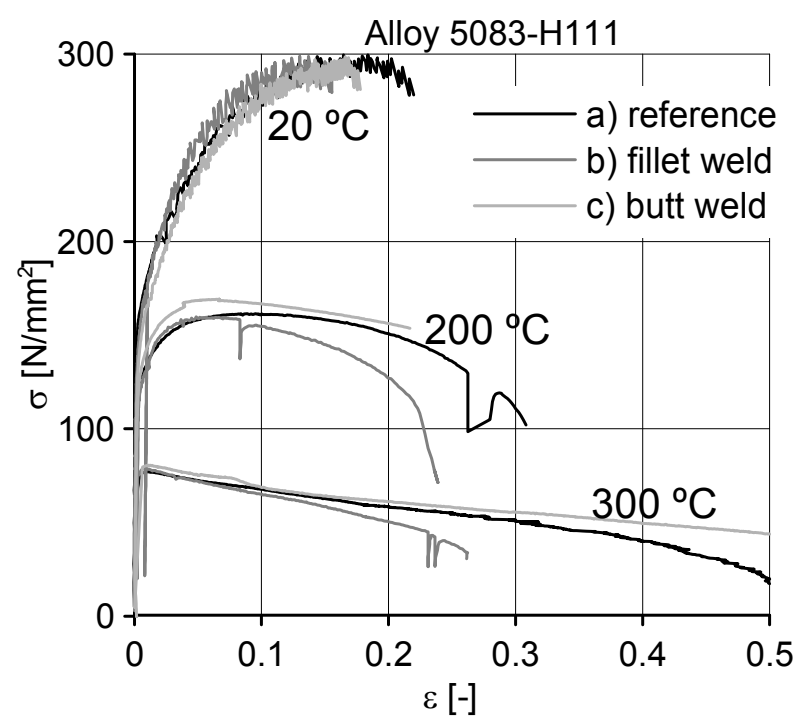

Figure 9. $\sigma-\varepsilon$ Relationships for Alloy 5083-H111
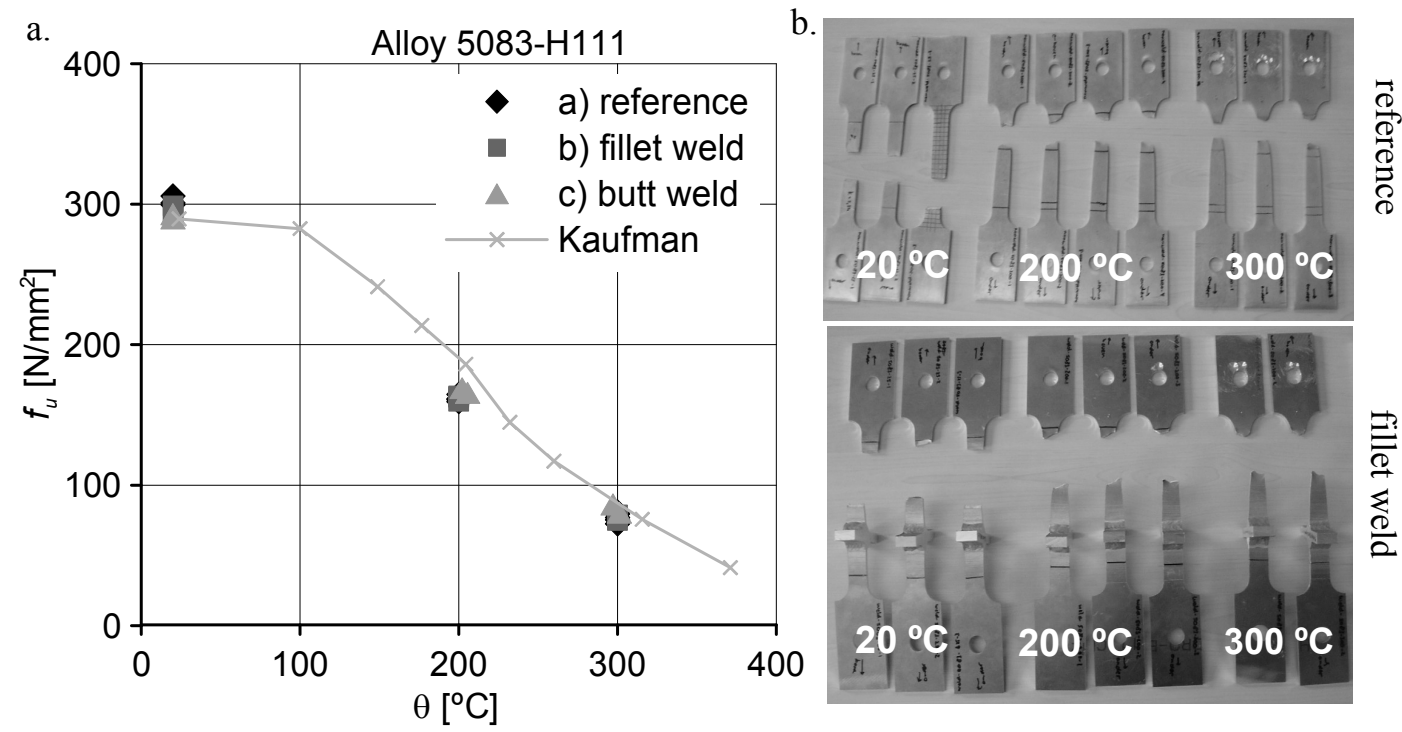

Figure 10. Test Results of Specimens of Alloy 5083-H111

(a. $f_{u}$ as Function of $\theta$; b. Specimens after Testing) 
Figure 11a gives $f_{u}$ as a function of $\theta$ for the specimens of the artificially aged alloy 6060-T66. There was a substantial difference in $f_{u}$ between the welded and reference specimens at room temperature. This difference in strength decreased with increasing temperature. At $300{ }^{\circ} \mathrm{C}$, the strength of the welded specimens was approximately equal to that of the unwelded specimens. There was no significant difference in strength between the fillet weld specimens and the butt weld specimens.

All specimens failed near to the centre of the specimen (i.e. in the HAZ) at room temperature. At $200{ }^{\circ} \mathrm{C}$, rupture took place in the upper part of the parallel length for the reference specimens, whereas the welded specimens failed in the HAZ. Rupture took place at the upper part of the parallel length (i.e. outside the HAZ) in the case of welded and reference specimens at $300{ }^{\circ} \mathrm{C}$ (Figure 11b.)
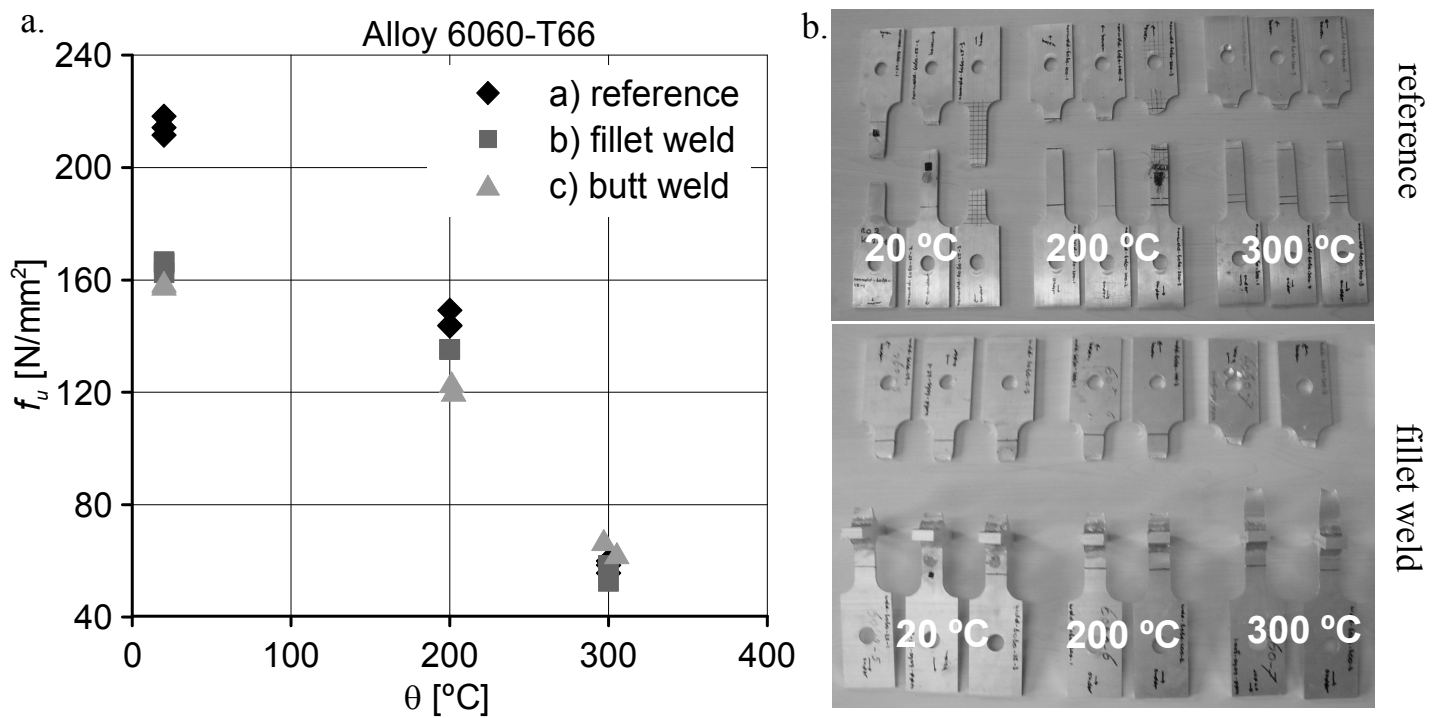

Figure 11. Test Results of Specimens of Alloy 6060-T66 (a. $f_{u}$ as Function of $\theta$; b. Specimens after Testing)

Figure 12a. gives $f_{u}$ as a function of $\theta$ for the specimens of the artificially aged alloy 6082-T6. For reference, the Figure also gives the strength according to tests on parent material carried out by Langhelle [13]. There was a large difference in $f_{u}$ between the welded and reference specimens at room temperature. This difference in strength decreased with increasing temperature, but a difference in strength remained present for all test temperatures. For the welded specimens, rupture took place in the heat affected zone at all test temperatures (Figure 12b).

All welded steady-state specimens failed outside the weld metal, both at room and at elevated temperatures. 

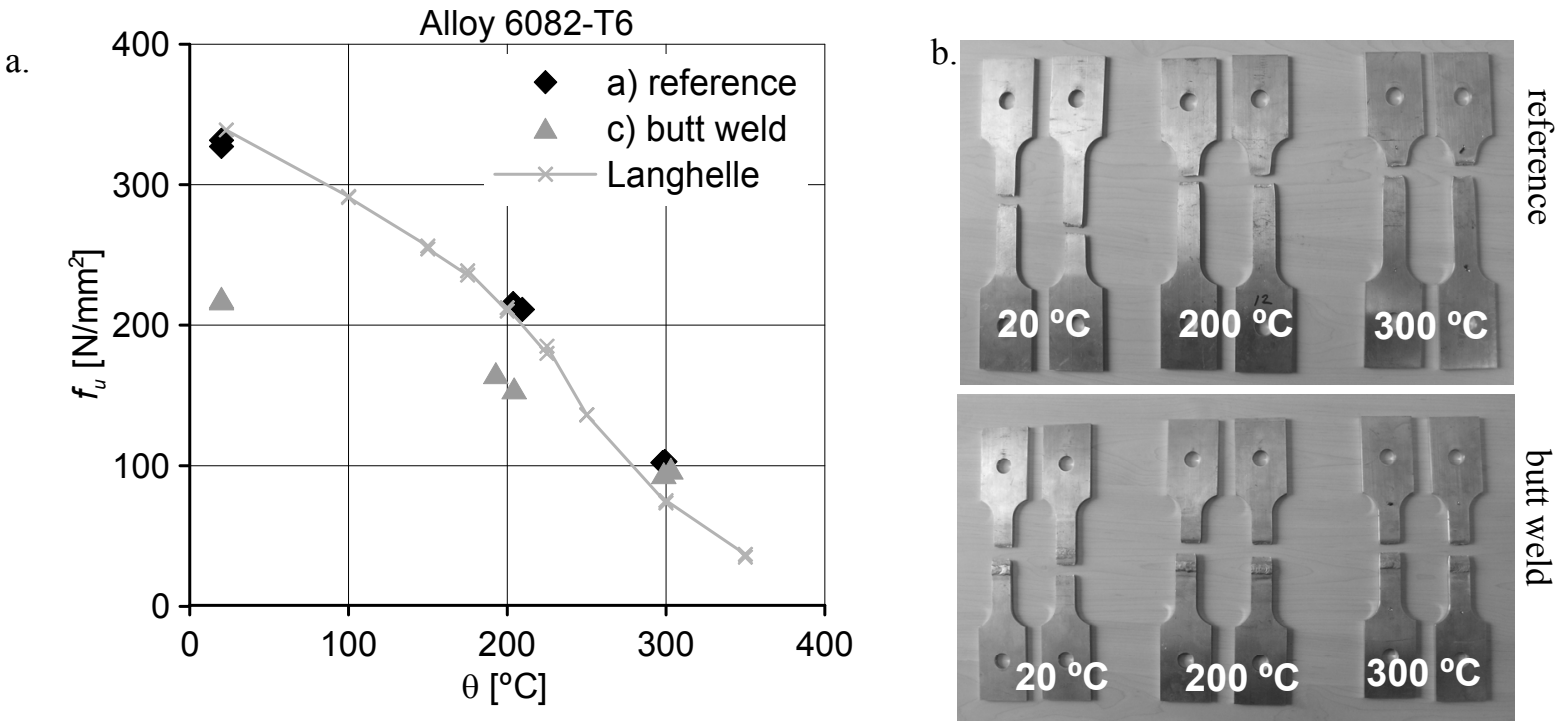

Figure 12. Test Results of Specimens of Alloy 6082-T6 (a. $f_{u}$ as Function of $\theta ; \mathrm{b}$. Specimens after Testing)

\section{Transient State Tests}

The transient state tests were carried out with a stress level equal to $f_{u}$ of the steady state tests at $300{ }^{\circ} \mathrm{C}$. Figure 13 gives the mechanical strain in axial direction as a function of the temperature of the tests carried out. The strain development was almost equal for the welded and the reference specimens.
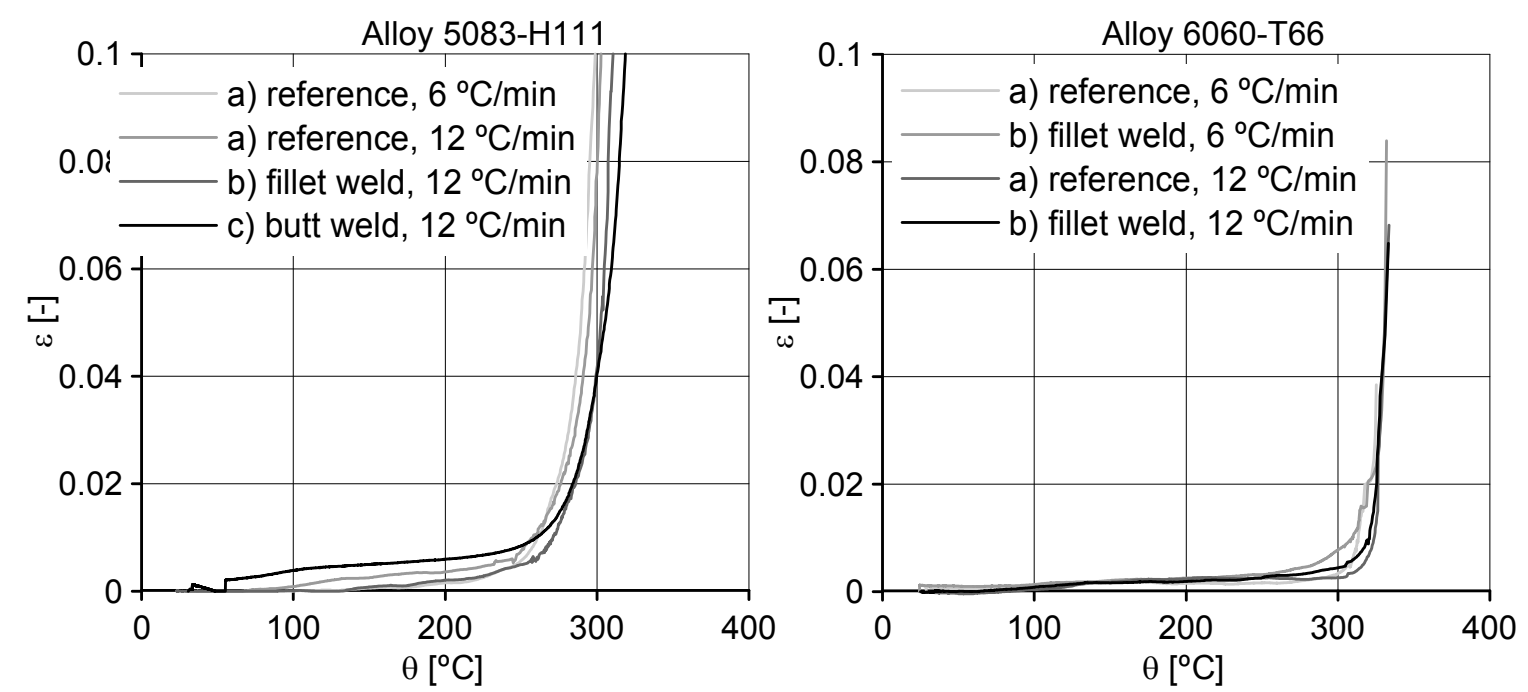

Figure 13. Axial Strain as a Function of the Temperature for the Transient State Tests (a. Alloy 5083-H111, b. Alloy 6060-T66)

All welded transient-state specimens failed outside the weld metal.

\subsection{Discussion of the Results}

The weld throat of the fillet weld specimens was chosen such that the specimens would not fail at the weld. For the butt weld specimens, however, the weld throat was determined by the specimen thickness. 
None of the tested specimens failed at the weld itself. This means that the weld itself is not decisive for the strength in the case of butt weld specimens with the applied combinations of alloy and filler metal and the applied overmatch of the weld throat: The weld throat was approximately $5.5 \mathrm{~mm}$ and the plate thickness was $5 \mathrm{~mm}$.

The strength of the reference specimens represented the strength of the parent metal. The strength of the welded specimens is considered to represent the strength of the HAZ. The strength of the HAZ is considered to be independent of the weld type (fillet or butt).

The steady-state tests on the artificially aged alloys showed that the difference in strength between welded and reference specimens decreased as the temperature increased. This is attributed to the fact that the favourable structure of treated alloys is already destroyed by welding in the HAZ, so that heating by fire has a smaller impact than in case of treated parent metal. This is in agreement with the conclusion drawn in section 3, that work hardening and/or precipitation hardening has almost no influence on the strength at temperatures above $150-200{ }^{\circ} \mathrm{C}$. The transient state tests also showed an almost equal failure temperature for the parent metal and for the heat affected zone.

In conformity with EN 1999-1-1, the ratio between $f_{u}$ of the HAZ and $f_{u}$ of the parent metal is denoted with $\rho_{u, h a z}$. Figure 14 a. gives $\rho_{u, h a z}$ resulting from the tests as a function of the temperature. The values specified in EN 1999-1-1 for $\rho_{u, h a z}$ at room temperature are 0.56 for alloy 6060-T66 and 0.64 for alloy 6082-T6. $\rho_{u, h a z}$ in the standard agrees well with that of the tests for alloy 6082-T6. For alloy 6060-T66, however, $\rho_{u, \text { haz }}$ resulting from the tests is higher than the value in the standard.

The partial factor for $f_{0.2}$ of the parent metal at room temperature in EN 1999-1-1 is equal to $\gamma_{M I}=$ 1.1. For $f_{u}$ of the HAZ at room temperature, the partial factor is equal to $\gamma_{M 2}=1.25$. The HAZ is not decisive in the design if the following condition is fulfilled:

$$
\frac{f_{u, h a z}}{f_{0,2, \text { parent }}} \frac{\gamma_{M 1}}{\gamma_{M 2}}>1 \Rightarrow \frac{f_{\text {u,haz }}}{f_{0,2, \text { parent }}}>1.136
$$

The partial factor for material properties for fire is equal to $\gamma_{M, f i}=1.0$.

Figure $14 \mathrm{~b}$. gives the ratio $f_{u, \mathrm{HAZ}} / f_{0.2 \text {, parent metal }}$ as a function of the temperature for the artificially aged alloys. This ratio increases for increasing temperature in case of alloy 6060-T66. For alloy 6082-T6, this ratio is slightly smaller at $200{ }^{\circ} \mathrm{C}$ compared to the test at room temperature. However, the ratio according to the tests at $200{ }^{\circ} \mathrm{C}$ (ratio $=0.76$ ) is still larger than this ratio at room temperature according to EN 1999-1-1 (ratio = 0.74). At $300^{\circ} \mathrm{C}$, the $\mathrm{HAZ}$ is (almost) not decisive for both alloys.

The number of tests carried out was limited. Moreover, transient state data are missing for aluminium alloys. Therefore, it is considered inappropriate to use the values found for $\rho_{u, h a z}$ directly in design. However, it is shown in tests and theoretically explained that $\rho_{u, h a z}$ increases with increasing temperature. It is a safe, but conservative approach, to use the same values for $\rho_{u, h a z}$ at elevated temperatures as at room temperature. 

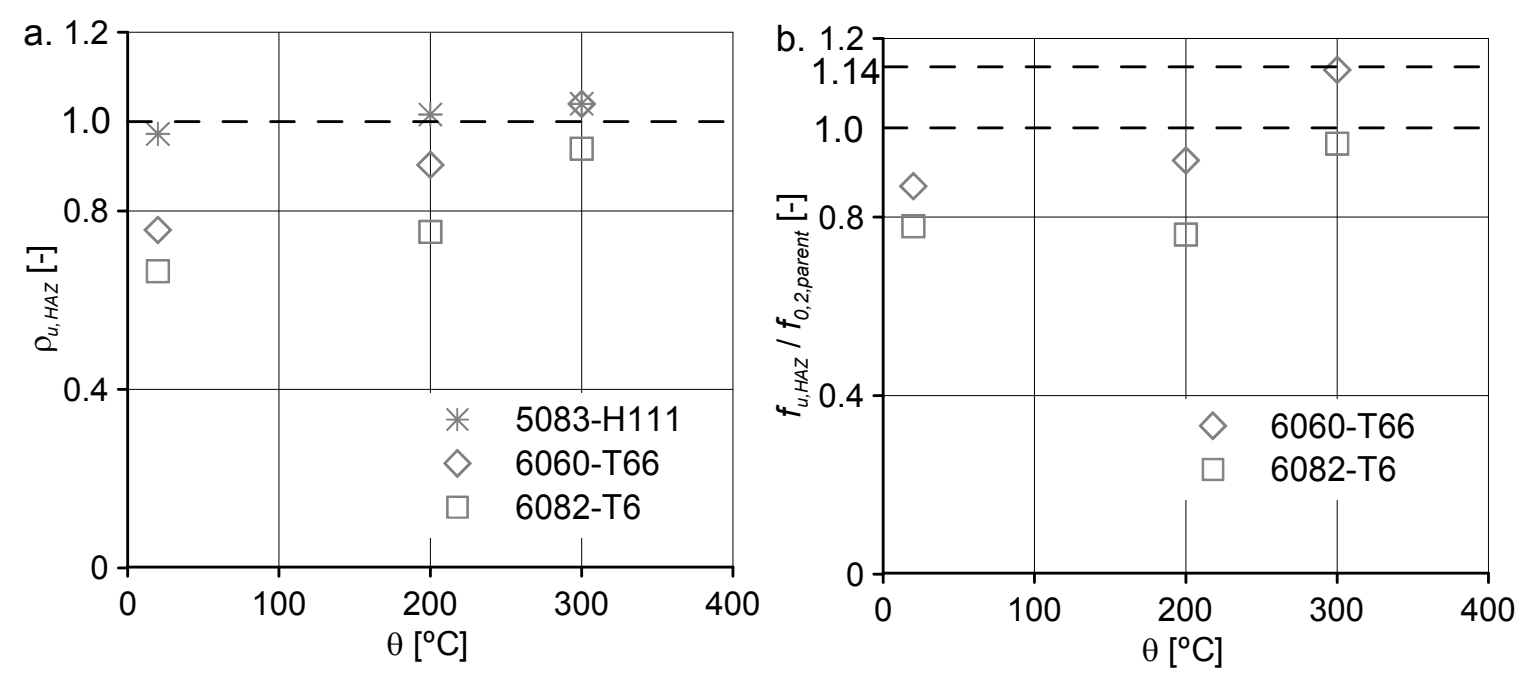

Figure 14. Steady State Strength of the Heat Affected Zone Compared to Steady State Strength of the Parent Metal (a. Ratio $f_{u, H A Z} / f_{u, \text { parent }}$; b. Ratio $f_{u, H A Z} / f_{0.2, \text { parent }}$ )

\section{CONCLUSIONS AND RECOMMENDATIONS}

The following conclusions are drawn, based on this research:

- In case of treated (hardened) aluminium alloys, the strength of the heat affected zone (HAZ) is lower than that of the parent metal. This is due to the fact that the favourable metal structure obtained by the treatment is (partially) destroyed by the heat input due to welding. In addition, the strength of the weld metal is for a number of alloys lower than that of the parent metal. Consequently, the HAZ or the weld metal are often decisive for the strength of connections in room temperature design, and dimensions of components often depend on the strength of the HAZ or the weld metal.

- The tests carried out at elevated temperature show that the difference in strength between the HAZ and the parent metal decreases with increasing temperature. This is due to the fact that the favourable metal structure obtained by a treatment is already destroyed by the heat input at welding. Consequently, heating by a fire has a smaller impact on the strength of the HAZ than on the strength of the treated parent metal.

- It is a safe but conservative approach to assume that the values for the relative strength of the heat affected zone as given in EN 1999-1-1 for room temperature, $\rho_{u, h a z}$, also apply in fire.

- A simple calculation rule in EN 1999-1-2 states that the connection need not be checked, provided that the thermal resistance of the fire protection at the connection is at least as high as that of the adjacent members. In general, the ratio between the ultimate tensile strength of the HAZ and the $0.2 \%$ proof stress of the parent metal $\left(f_{u, H A Z} / f_{0.2, \text { parent }}\right)$ increases slightly with increasing temperature. Therefore, the simple calculation rule in EN 1999-1-2 is justified, at least for the tested alloys (5083-H111, 6060-T66 and 6082-T6). Considering the fact that the strength degradation of alloys in the same series and the same temper is almost equal, it is expected that the simple calculation rule is justified for all 5xxx alloys in annealed temper and all $6 \times x x$ alloys in artificially aged temper; 
- The tests carried out in this research on butt welded specimens of alloy 5083-H111 with fillet metal 5356, alloy 6060-T66 with fillet metal 4043 and alloy 6082-T6 with fillet metal 4043, show that the weld metal is not decisive for the strength, both at room and at elevated temperature.

The conclusions in this paper are based on a limited number of tests on three often applied aluminium alloys. It is therefore considered inappropriate to implement the data resulting from this test program in EN 1999-1-2 without further research. It is recommended to carry out a larger test programme, which should be focussed especially on transient state tests.

The simple calculation rule in EN 1999-1-2 - the connection need not be checked provided that the thermal resistance of the fire protection at the connection is at least as high as that of the adjacent members - should be accompanied by the prerequisite that the utilisation of the connection should not be larger than the utilisation of the connected members (as in EN 1993-1-2).

\section{ACKNOWLEDGEMENTS}

This research was carried out under project number MC1.02147 in the framework of the Strategic Research programme of the Netherlands Institute for Metals Research in the Netherlands (www.nimr.nl).

The members of the joint industry project group "fire design of aluminium structures", The Netherlands, are kindly acknowledged for their contribution.

\section{REFERENCES}

[1] Lundberg, S., "Mechanical Properties at Elevated Temperature for Aluminium Alloys CEN/TC 250/SC 9/PT Fire/N-27”, 2003.

[2] Kammer, C., "Aluminium Taschenbuch teil 1", Grundlagen und Werkstoffe Aluminium Verlag, Düsseldorf, 2002.

[3] Maljaars, J., Soetens, F. and Twilt, L., "Heating of Aluminium Members Exposed to Natural Fire Conditions", Proceedings of SIF'06, 2006, Vol. 1, pp. 75-88.

[4] EN 1999-1-2 Eurocode 9: Design of Aluminium Structures - Part 1-2: General Rules Structural Fire Design, 2006.

[5] EN 1999-1-1 Eurocode 9: Design of Aluminium Structures - Part 1-1: General Structural Rules, 2007.

[6] Altenpohl, D., Aluminium Viewed from within, Aluminium-Verlag, Düsseldorf, 1982.

[7] Gitter, R., "Aluminium Materials for Structural Engineering - Essential Properties and Selection of Materials", Structural Engineering International, 2006, Vol. 4/2006.

[8] Dwight, J., “Aluminium Design and Construction”, Spon, London, 1999.

[9] Soetens, F., "Welded Connections in Aluminium Alloy Structures", Heron, Vol. 32, 1987.

[10] Voorhees, H.R. and Freeman, J.W., "Report on the Elevated-temperature Properties of Aluminium and Magnesioum Alloys", Americal Society of Testing Materials, STP No. 291, 1960.

[11] Kaufman, J.G., "Properties of Aluminium Alloys - Tensile, Creep and Fatigue Data at High and Low Temperatures, ASM International, Materials Park, 1999.

[12] Hepples and Wale High Temperature Tensile Properties of 6082-T651, Technical Assistance Report No. BTAR-93/024, Alcan Banbury Laboratory, 1992. 
[13] Langhelle, N.K., "Experimental Validation and Calibration of Nonlinear Finite Element Models for Use in Design of Aluminium Structures Exposed to Fire", Norwegian University of Science and Technology : Trondheim, 1999, ISBN 82-471-0376-1.

[14] Kumar, D.R. and Swaminathan, K., "Tensile Deformation Behaviour of Two Aluminium Alloys at Elevated Temperatures", Materials at High Temperatures, 1999, Vol. 16, pp. 161-172.

[15] Van den Boogaard Thermally Enhanced Forming of Aluminium Sheet, PhD dissertation, University of Twente, The Netherlands, 2002.

[16] Maljaars, J., Fellinger, J.E.J. and Soetens, F., "Fire Exposed Aluminium Structures", Heron, 2005, Vol. 50-4, pp. 261-278.

[17] EN 1993-1-2 Eurocode 3: Design of Steel Structures - Part 1-2: General Rules - Structural Fire Design, 2005.

[18] Franssen, J.M. and Zaharia, "Steel Structures Subjected to Fire, $2^{\text {nd }}$ Edition, University of Liege, Belgium, 2006.

[19] EN 10002-5 - Metals - Tensile Test - Part 5: Test Method at elevated temperature, 1992. 